measured individually to the nearest $\mathrm{mm}$. and weighed to the nearest $10 \mathrm{mgm}$., two of the original sample were discarded owing to damage, one of them parasitized. The value of $K$ used $(5 \cdot 14)$ is such that a normal fish has the shape-index of $1 \cdot 0$, in other words, of the 138 fishes measured, 69 had an index of less than 1.0 and 69 greater than 1.0 . The shape-index of each fish is plotted against its length in Fig. 2. On the left side of the figure are the fishes without parasites and on the right, for comparison, are the smaller number with parasites. The pattern of distribution shown in this figure is sub. stantially the same for both groups of fishes. Of the 42 parasitized fishes measured, 25 had a shape index greater than, and 17 less than, unity ; and of the 96 healthy fishes 44 had an index greater than, and 52 less than, unity. This would indicate a beneficial effect of the parasite on the weight of the fish, but the difference is slight and probably not statistically significant.

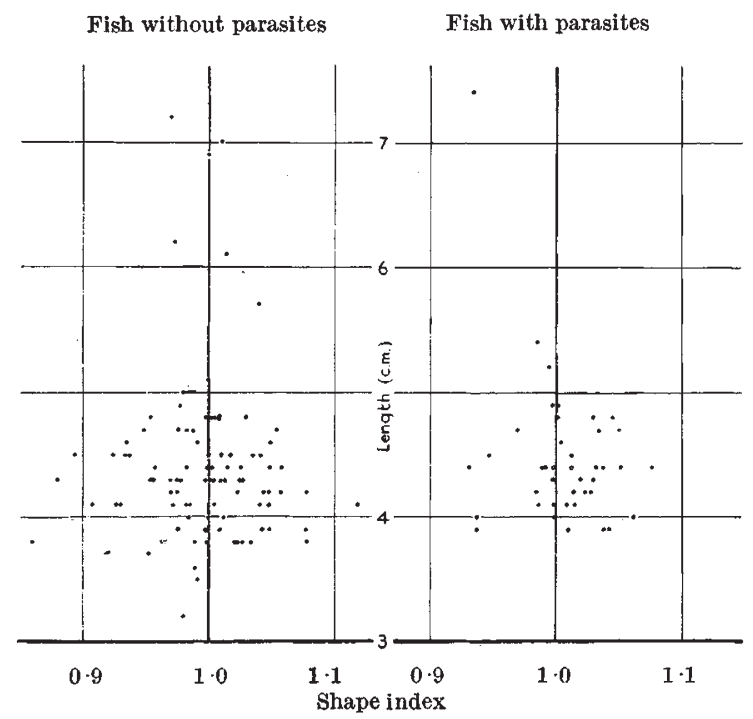

Fig. 2. Shape index and length distributions of parasitized and normal fishes

The lengths of the fishes shown in Fig. 2, varying from $3 \cdot 2$ to $7 \cdot 4 \mathrm{~cm}$. in standard length, fall within the size range given by Robertson ${ }^{4}$ for samples of whitebait sprats from the Thames Estuary, which he considered to be mainly composed of 0-group fishes. The considerable size-range is probably a reflexion of the prolonged spawning season of sprat in the North Sea-March to August (maximum in June); and the few large fishes, one of which was parasitized, were probably spawned early in the season and were thus 1-group or close to it when caught. This conclusion, which is in conformity with Robertson's findings, was supported by an examination of the few scales present on two of the large sprats which appeared to be those of 1-group fishes.

$$
\text { J. P. HARDing }
$$$$
\text { A. C. WhEeler }
$$

British Museum (Natural History), London, S.W.7.

1 Leigh-Sharpe, W. H., Parasitology, 27, 270 (1935).

"Scott, T., and Scott, A., "The British Parasitic Copepoda" (Ray Society, 1913).

s Nakai, N., J. Imp. Fish. Inst., Tokyo, 23, 39 (1927).

4 Robertson, J. A., Fish. Invest., (2), 16, 103 (1938).

\section{Movement of Salmon on the River Erne}

A GRAPHIC record of salmon (Salmo salar) ascending the fish pass at Cathaleen's Fall Hydro-Electric Generating Station has been kept for four fishing seasons. This station is one of two erected by the Electricity Supply Board, Ireland, on the River Erne. It is located at the toe of a dam across the river and has an installed capacity of $45,000 \mathrm{~kW}$. and a gross head of approximately $100 \mathrm{ft}$.

The fish ladder extends from the power station tailrace over the dam into the head waters. The tailrace is tidal. The ladder is of the White submergedorifice type similar to those developed and used by the North of Scotland Hydro-Electric Board at its Pitlochry and Clunie power stations. It has 73 pools with a difference in water-level of $1 \frac{1}{2} \mathrm{ft}$. between successive pools. Some of the bottom pools are, however, submerged except at low tide or when the turbines in the power station are not operating; some of the top pools are by-passed at low reservoir levels. Orientation of the pass is approximately east-west.

The counter is of the nylon-screen type developed by the Board and has as an accessory a recording voltmeter which shows on a chart the time of the passage of each fish through the counter.

A preliminary analysis of the results so far available indicates the following movements of salmon: $(a)$ an almost complete cessation of activity during hours of darkness ; $(b)$ greatest activity between noon and dusk; (c) the number of fish travelling singly is small in comparison with the total count.

$$
\text { P. A. JACKSON }
$$

Cathaleen's Fall Generating Station,

Ballyshannon,

Co. Donegal.

June 27.

\section{Pigmy Sperm Whale (Kogia breviceps) in Borneo}

IN recent years the Sarawak Museum has developed a system by which people along the west coast of Borneo report (if they have time) the occurrence of any beached cetacean. Partly by this means, and with the help of Malays and Dayaks, we have extended the local list from five to fourteen known forms in the past five years, advised and criticized by Dr. F. C. Fraser, of the British Museum (Natural History).

In 1956, and again in 1957, complete examples of the comparatively rare Bryde's whale (Balaenoptera bryde $i$ ) were obtained in this way, and on February 19 , 1958 , we were able to recover from Buntal in southwest Sarawak, a perfect specimen of the very littleknown pigmy sperm whale (Kogia breviceps). This miniature 10 -ft. version of the sperm whale-the greatest of all the toothed cetaceans-has not previously been recorded from this part of the world. Of added interest was the presence of a well-developed embryo. A beautiful baby, of a battleship-grey, it is $14 \frac{1}{2} \mathrm{in}$. long. Two of seven previously recorded embryos are from European waters.

Photographs and measurements have been sent to the British Museum (Natural History) for confirmation of identification.

TOM HARRISSON GEORGE JAMUH

Sarawak Museum, Borneo. 